\title{
A Phase II study of bosentan, a dual endothelin receptor antagonist, as monotherapy in patients with stage IV metastatic melanoma
}

\author{
Richard Kefford • Jane McNeil Beith • Guy Arthur Van Hazel • Michael Millward • \\ James Marshall Trotter • David Keith Wyld • Rada Kusic • Revati Shreeniwas • \\ Adele Morganti · Andrea Ballmer · Eleonor Segal • Oliver Nayler • Martine Clozel
}

Received: 20 June 2006 / Accepted: 12 September 2006 / Published online: 5 October 2006

(C) Springer Science + Business Media, LLC 2006

Summary There is no effective systemic therapy for disseminated metastatic melanoma. Data suggest that endothelin may play a role in pathophysiology of melanoma and that the dual endothelin receptor antagonist bosentan may have anti-tumor activity.

This multicenter, open-label, single-arm, prospective, proof-of-concept study assessed the effects of bosentan monotherapy (500 mg oral tablets, bid) on tumor response in patients with stage IV metastatic melanoma. Patients were treated until disease progression, death or serious adverse event leading to premature study drug discontinuation. Tumor response was assessed at 6-weekly intervals

\author{
R. Kefford $(\square) \cdot$ R. Kusic \\ Westmead Institute for Cancer Research, University of Sydney at \\ Westmead Hospital \& Westmead Millennium Institute, \\ Westmead, NSW 2145, Australia \\ e-mail: rick_kefford@wmi.usyd.edu.au \\ J. M. Beith · M. Millward \\ Sydney Melanoma Unit at Royal Prince Alfred Hospital, \\ Camperdown, Australia \\ G. A. Van Hazel \\ Perth Oncology Group, \\ Perth, Australia \\ J. M. Trotter \\ Royal Perth Hospital, \\ Perth, Australia \\ D. K. Wyld \\ Royal Brisbane Hospital, \\ Brisbane, Australia \\ R. Shreeniwas · A. Morganti · A. Ballmer - E. Segal · O. Nayler · \\ M. Clozel \\ Actelion Pharmaceuticals Ltd., \\ Allschwil, Switzerland
}

using the Response Evaluation Criteria in Solid Tumors (RECIST).

Among the 35 patients included in this study with stage IV metastatic melanoma, 21 (60\%) were stage M1C, 10 (29\%) stage M1B and 4 (11\%) stage M1A (American Joint Committee on Cancer [AJCC] classification). Nine patients (26\%) had received prior therapy for stage IV melanoma. Disease stabilization was observed in 6 of the 32 patients analyzed per protocol at week 6 with confirmatory evaluation at week 12,5 of whom were still stable at $\geq 24$ weeks. Of the 6 patients with disease stabilization, 2 were stage M1A, 1 was stage M1B and the remaining 3 were stage M1C. Partial or complete response was not observed. Progressive disease was observed in 17 (49\%) patients at week 12 and in 25 (71\%) patients at the end of the study (data base closure). The most frequent adverse events were typical for the underlying disease or known to be associated with bosentan: headache $(43 \%)$, fatigue $(34 \%)$, nausea (31\%), back pain $(23 \%)$ and abnormal hepatic function (23\%).

Bosentan might have benefit in disease stabilization in certain patients with metastatic melanoma and deserves further investigation in combination with other anticancer drugs.

Keywords Bosentan · Endothelin receptor · Metastatic melanoma

\section{Introduction}

Patients with metastatic malignant melanoma have an unfavorable prognosis. Patients with extra-pulmonary visceral involvement, or an elevated serum lactate dehydrogenase (LDH) have a median survival of 4-6 months and a 2-year survival of $\leq 5 \%$ [1]. There is no effective treatment for metastatic melanoma, as there is no evidence from randomized controlled trials that any form of systemic therapy 
prolongs overall survival [2-4]. Single agent treatment with dacarbazine (dimethyl triazeno imidazole carboxamide, DTIC) remains the reference standard treatment for stage IV melanoma, yet in recent Phase III prospective randomized trials response rates were only $6.8-13 \%$ [5-7].

The present study involves a novel approach to treatment of melanoma by antagonism of endothelin (ET) receptors $\mathrm{ET}_{\mathrm{A}}$ and $\mathrm{ET}_{\mathrm{B}}$. The ET system, and the $\mathrm{ET}_{\mathrm{B}}$ receptor in particular, plays a fundamental role in the physiology of melanocytes [8-10]. Activation of $\mathrm{ET}_{\mathrm{B}}$ receptors by ET-1 promotes proliferation of melanogenic precursor cells and inhibits their differentiation, two characteristic features of melanoma genesis [11]. Furthermore, ET-1 mediates ultraviolet light-induced melanin synthesis in human melanocytes [12]. In melanocytes and melanoma cells, ET-1 increases the expression of the melanoma invasion promoter MCAM (melanoma cell adhesion molecule) while decreasing expression of the melanoma invasion suppressor E-cadherin $[13,14]$. In human melanoma, $\mathrm{ET}_{\mathrm{B}}$ receptor expression is upregulated and the increased expression is correlated with tumor progression [15]. Consistent with these observations, $\mathrm{ET}_{\mathrm{B}}$ receptor blockade with BQ788 inhibits growth, causes re-differentiation and induces cell death of human melanoma cell lines [16].

The endothelin system may contribute to tumor growth and progression by multiple mechanisms, including cell proliferation, angiogenesis, and escape from apoptosis [17]. Bosentan, a non-peptide orally active dual $\mathrm{ET}_{\mathrm{A}}$ and $\mathrm{ET}_{\mathrm{B}}$ receptor antagonist, inhibited melanoma cell proliferation in vitro in all examined cell lines and in a mouse xenograft model [18]. Bosentan reversed ET-1-induced inhibition of apoptosis [19] and potentiated Fas ligand-mediated apoptosis in melanoma, as well as in colon carcinoma, and glioblastoma cells [19-21]. Furthermore, bosentan inhibited ET-1mediated angiogenesis [22]. The role of the ET system in the pathophysiology of melanoma and the experimental data with endothelin receptor antagonists provide the rationale to assess bosentan in a proof-of-concept study in patients with metastatic melanoma.

The primary objective of this study was to evaluate the effect of bosentan on tumor response when administered as first- or second-line therapy to patients with stage IV metastatic melanoma. The secondary objective was to evaluate safety and tolerability of bosentan in this patient population.

\section{Dose selection}

Bosentan is an established treatment of pulmonary arterial hypertension [23] and is well tolerated in this patient population at a dose of $125 \mathrm{mg}$ bid. However, the study dose was selected to maximize potential benefit to the patient and pro- vide a sufficient exposure to the skin to block ET receptors and potentially inhibit tumor growth. The $\mathrm{IC}_{50}$ for bosentan to inhibit the growth of melanoma cell lines in vitro measured by $\mathrm{H}^{3}$-thymidine incorporation is around $30 \mu \mathrm{g} / \mathrm{ml}$ [18]. To attain in vivo bosentan concentrations closer to this $\mathrm{IC}_{50}$ value, a dose of $500 \mathrm{mg}$ bid was chosen. This higher dose has been generally well tolerated in previous bosentan trials [24].

\section{Patients and methods}

The study was performed in 5 centers in Australia. Eligible patients were males or females $\geq 18$ years with histologically proven metastatic melanoma, measurable stage IV disease according to the Response Evaluation Criteria in Solid Tumors (RECIST), no evidence of central nervous metastasis or carcinomatous meningitis, Eastern Cooperative Oncology Group (ECOG) performance status $\leq 1$ and a life expectancy $>12$ weeks. Patients must have had no prior systemic therapy, or failed no more than one prior course of systemic therapy for metastatic melanoma. Patients could not be included if they had: alanine aminotransferase (ALT) and/or aspartate aminotransferase (AST) $>3$ times the upper limit of normal (ULN), or $>2$ times ULN and total bilirubin $>2.0 \mathrm{mg} / \mathrm{dl}$, lactate dehydrogenase $(\mathrm{LDH})>1.5$ times ULN, systolic blood pressure $<85 \mathrm{mmHg}$, chronic heart failure New York Heart Association Class III or IV or hemoglobin $<30 \%$ the lower limit of normal.

Prohibited concomitant therapies included other therapies for melanoma as well as cyclosporine A, tacrolimus and glibenclamide (glyburide).

The study was conducted in full compliance with the principles of the Declaration of Helsinki and Good Clinical Practice. The protocol was approved by the independent ethics committee at the study sites. Voluntary written informed consent was obtained from all patients prior to enrolment into the study.

\section{Treatment}

Bosentan was administered in an open-label fashion until disease progression, death or an adverse event leading to study drug discontinuation occurred.

The treatment regimen consisted of 4 tablets of bosentan, i.e., $500 \mathrm{mg}$ bid administered orally. Bosentan had to be discontinued if hepatic aminotransferases were $>8$ times ULN. The dose of bosentan was reduced to $250 \mathrm{mg}$ bid if there was an increase in aminotransferases $>3$ and $<8$ times the ULN. If 1 week later, aminotransferases were as high or further increased, the dose of bosentan was reduced to $125 \mathrm{mg}$ bid. One week later, if aminotransferases were as high or further increased, bosentan was discontinued. 
Regardless of the aminotransaminase levels, dose increase was not allowed after dose reduction.

\section{Treatment evaluation}

All patients underwent tumor staging that included for example a computerized tomography (CT) scan or magnetic resonance imaging (MRI) of the brain, chest and abdomen within the 28 days before treatment initiation. During treatment, physical examination and tumor staging by CT scans or MRI of chest and abdomen were repeated every 6 weeks.

Laboratory tests performed at screening and at regular interval during the study included: hemoglobin, bilirubin, ALT, AST, LDH, alkaline phosphatase, sodium, potassium, creatinine, and if applicable, pregnancy tests.

Safety and tolerability assessments included Adverse Events (AEs) and Serious Adverse Events (SAEs).

Tumor biopsy specimens were obtained before treatment from 5 patients with cutaneous lesions in order to evaluate the gene expression levels of $\mathrm{ET}_{\mathrm{A}}$ and $\mathrm{ET}_{\mathrm{B}}$ receptors and their ligands ET-1, ET-2 and ET-3. Specimens were cut in half and two independent RNA isolations were performed. Total RNA was reverse transcribed using random hexamers. Real-time quantitative PCR was performed with an SDS 7000 system using the TaqMan ${ }^{\circledR}$ Universal PCR Master Mix and specific TaqMan ${ }^{\circledR}$ Gene Expression assays (human $\mathrm{ET}_{\mathrm{A}}$ receptor: Hs00609865_m1; ET-1: Hs00174961_m1; ET-2: Hs00266516_m1 and ET-3: Hs00171177_m1). For human $\mathrm{ET}_{\mathrm{B}}$ receptor, specific $\mathrm{TaqMan}^{\circledR}$ probes were designed: Forward 5'GGGCCACTCCGCTTTTG-3', Reverse 5'-CCCTTGGGCCATAAGGTCTT-3', TaqMan ${ }^{\circledR}$ probe $5^{\prime}$-(FAM-CCGCAGAGATAATGACGCCACCCACTAMRA)-3' . All reactions were multiplexed and normalized to $18 \mathrm{~S}$ rRNA probes and done in duplicate. All agents and software were from Applied Biosystems, USA.

\section{Response criteria and statistical analysis}

An objective tumor response was defined as complete response, partial response or stable disease according to the RECIST criteria [25].

The primary efficacy endpoint for this study was the tumor objective response rate, defined as the proportion of patients with an objective response at week 6 and confirmatory evaluation at week 12 . The objective response rate was primarily analyzed in the per-protocol patient set consisting of all treated patients who had an assessment of the primary endpoint and had no major protocol deviations that might impact the evaluation of the primary endpoint. The duration of response and the best overall response were analyzed in the all-treated patient set. All efficacy endpoints were analyzed descriptively by means of appro- priate statistics, using proportions, Kaplan-Meier estimates, means, medians, and standard deviations. Two-sided $95 \%$ confidence intervals (CIs) based on the binomial exact distribution were determined for proportions.

Safety and tolerability endpoints and the evaluation of baseline characteristics were analyzed in the all-treated patient set.

\section{Results}

Baseline characteristics and patient disposition

Between 24 March 2003 and 31 October 2003, 35 patients were enrolled in this proof-of concept study. Demographic and clinical characteristics of patients at baseline are summarized in Table 1.

The majority of patients had advanced disease according to the AJCC classification (60\% were stage M1C). Elevated $\mathrm{LDH}$, a marker of tumor burden, was observed in all patients.

Table 1 Baseline demographic and clinical characteristics

\begin{tabular}{ll}
\hline Total number of patients & 35 \\
Median age & 61.0 years $(32-79)$ \\
Gender & \\
Male & $22(63 \%)$ \\
Female & $19(37 \%)$ \\
AJCC stage & $4(11 \%)$ \\
M1A & $10(29 \%)$ \\
M1B & $21(60 \%)$ \\
M1C & $4.3(1-10)$ \\
Mean total of lesions per patient & \\
Most common lesions & $69 \%$ \\
Lung & $34 \%$ \\
Lymph nodes & $26 \%$ \\
Liver & $17 \%$ \\
Skin & $14 \%$ \\
Adrenals & 35 \\
Elevated LDH & 9 \\
Prior treatment for metastatic & \\
melanoma & 5 \\
DTIC (monotherapy or & \\
in combination) & 4 \\
Others & 8.8 weeks $(1.1-40.1)$ \\
Mean duration of bosentan & \\
treatment & $1 / 17 / 25^{*}$ \\
Study drug discontinuation before & $25 / 33$ \\
week 12/before week 24 & \\
Progressive disease & \\
Adverse Event & \\
Withdrawal of consent & \\
Death & \\
\hline
\end{tabular}

AJCC: American Joint Committee on Cancer; DTIC: dacarbazine; LDH: Lactate dehydrogenase.

*One patient experienced at the same time an $\mathrm{AE}$ and disease progression. 
Table 2 Patients with stable disease $\geq 12$ weeks of treatment

\begin{tabular}{llllcl}
\hline Patient & Age (years)/gender & AJCC stage at baseline & LDH at baseline (U/l) & $\begin{array}{l}\text { Stable disease } \\
\text { duration (days) }\end{array}$ & $\begin{array}{l}\text { Reason for study drug } \\
\text { discontinuation }\end{array}$ \\
\hline 311 & $67 / \mathrm{M}$ & M1A & 136 & 193 & Progressive disease \\
502 & $74 / \mathrm{M}$ & M1A & 391 & $>844$ & Not applicable \\
306 & 50/M & M1B & 140 & 210 & Progressive disease \\
510 & 66/F & M1C & 518 & 116 & Progressive disease \\
101 & 66/M & M1C & 217 & 173 & Progressive disease \\
$102^{*}$ & 72/F & M1C & 193 & $>800$ & Not applicable \\
\hline
\end{tabular}

*Patient 102 was diagnosed with non-Hodgkin lymphoma at Day 844.

AJCC: American Joint Committee on Cancer; F: female; LDH: lactate dehydrogenase; M: male.

The majority of patients 28/33 (85\%) had an ECOG status of 0 (data were not available for 2 patients). Lesions were predominantly in the lung, lymph nodes, liver, skin and adrenal glands. Nine patients had received prior therapy for stage IV melanoma. One patient, in deviation from the protocol, was enrolled in the study despite a brain metastasis.

All 35 enrolled patients were analyzed in the all-treated patient set, but only 32 in the per-protocol patient set. Three patients were excluded from the per-protocol population because no tumor response evaluation was performed.

All patients received the intended dose of $500 \mathrm{mg}$ bid and only 1 patient had a dose reduction to $250 \mathrm{mg}$ bid, after 124 days of treatment, due to elevated hepatic aminotransferases. The mean treatment duration was 8.8 weeks, with a range of 1.1 to 40.1 weeks. Only 8 patients (24\%) received study drug for at least 12 weeks. A total of 25 patients prematurely discontinued study drug before week 12 , while 33 discontinued before week 24 . The reasons for study drug discontinuation in those patients with stable disease at 12 weeks of treatment are summarized in Table 2. The two last patients (102 and 502) continued on study drug beyond week 24 and are undergoing long-term follow up.

\section{Efficacy}

At 12 weeks of treatment, 6 patients had stable disease (see Table 2), resulting in an objective response rate of $18.8 \%$ (95\% CI: $7.2-36.4 \%$ ) in the primary per-protocol 32-patient set, and $17.1 \%(95 \%$ CI: $6.6-33.6 \%)$ in the all-treated 35 -patient set. Five of them had still stable disease at 24 weeks, 5 of these 6 patients received bosentan as first-line treatment. Of the 6 patients with disease stabilization, 2 were stage M1A, 1 was stage M1B and the remaining 3 were stage M1C. No complete or partial response was observed. Progressive disease was observed in 17 (49\%) patients at week 12 and in $25(71 \%)$ patients at the end of the study.

The best overall response (best response from the start of treatment until progressive disease) was stable disease in 12 patients, i.e., $37.5 \%$ (95\% CI: $19.1-52.2 \%$ ) in the perprotocol set and $34.3 \%$ in the all-treated set. The mean dura- tion of stable disease in these patients was 144.5 days $(95 \%$ CI: 86-210 days).

At the time of last follow-up (July 2005), 2 patients (102 and 502) had stable disease for more than 800 days (26 months) and were still receiving bosentan. Patient 102 had cutaneous and abdominal lymph node metastases at enrolment. The cutaneous metastasis was excised in accordance with protocol for endothelin receptor analysis. Biopsy of the abdominal lymphadenopathy at day 844 showed follicular non-Hodgkin lymphoma. No further metastatic melanoma has developed. The size of the target lesions (lymph nodes) over treatment time for patient 502 is plotted in Fig. 1. At 26 months, lymph node size had decreased by more than $20 \%$. The ECOG score could be analyzed in 30 of the 35 patients in the all-treated set. At baseline, 26 of these 30 patients had an ECOG score of 0 , and 4 patients had a score of 1 . The overall ECOG score did not change in $18(60 \%)$ patients, worsened in $11(37 \%)$ patients and improved in $1(3 \%)$ patient.

Seven patients $(20 \%)$ died due to the underlying disease. One patient died while still being treated with bosentan, while the other 6 died after study drug discontinuation for progressive disease. None of the deaths was considered by investigators to be related to study drug. In the remaining

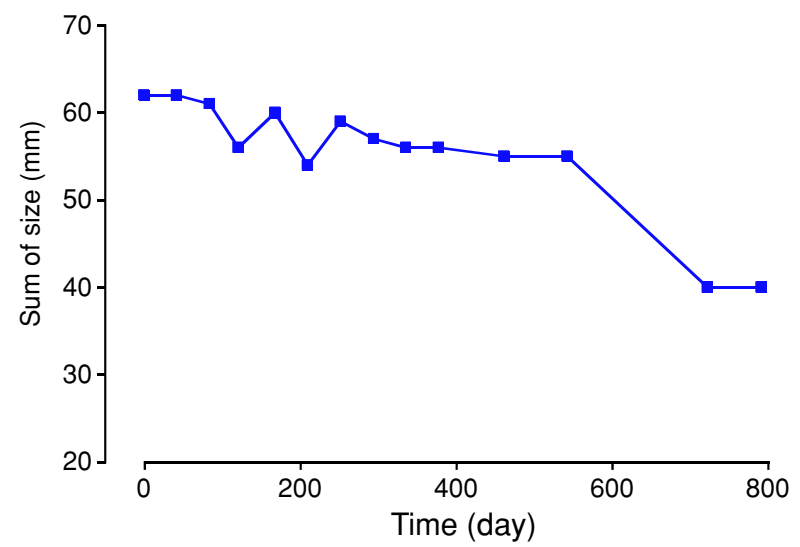

Fig. 1 Lymph node size $(n=3)$ over time as measured by CT scan (patient 502) 
28 patients, censored survival at the end of the study ranged from 22 to 363 days.

\section{Tumor biopsy results}

The RNA analysis from the 5 biopsy specimens showed that $\mathrm{ET}_{\mathrm{A}}$ receptor gene expression was homogeneously low, in contrast to high $\mathrm{ET}_{\mathrm{B}}$ receptor gene expression, although large differences in $\mathrm{ET}_{\mathrm{B}}$ receptor expression levels between specimens were observed. Within the same biopsy specimen, $\mathrm{ET}_{\mathrm{B}}$ receptor expression was at least 100- and up to 1000 -fold higher than $\mathrm{ET}_{\mathrm{A}}$ receptor expression. ET-1 was the predominantly expressed ligand and showed similar expression levels in all samples.

\section{Safety and tolerability}

A total of 20 SAEs were reported in 10 (29\%) patients. Those considered by the investigators to be related to study drug were: abnormal hepatic function in 4 patients, elevation of alkaline phosphatase in 2 patients and jaundice in 1 patient.

Of the total 210 AEs reported in 34 patients, 73 were considered to be related to study drug according to the investigators. The most frequent AEs were headache, fatigue, nausea, back pain, and abnormal hepatic function (Table 3). AEs leading to drug discontinuation were observed in $7(20 \%)$ patients: 5 for abnormal hepatic function, 1 for elevated alkaline phosphatase, 1 for hemorrhagic stroke, and 1 for weakness of an arm due to a brain metastasis. One of these patients had, as well, progressive disease at the time of study drug discontinuation.

Elevations in hepatic enzymes were observed in 12 patients. In 4 patients, modest increases not exceeding 3 times ULN were observed for a single hepatic enzyme. The remaining $8(23 \%)$ patients had aminotransferases $>3$ times the ULN with or without increase of other liver enzymes. They were reported as an AE leading to study drug discon-

Table 3 Adverse events

\begin{tabular}{lrrr}
\hline & \multicolumn{3}{c}{ Adverse events } \\
\cline { 2 - 4 } & & \multicolumn{2}{c}{ Patients } \\
\cline { 2 - 4 } & Events & $n$ & $\%$ \\
\hline Any & 210 & 34 & 97 \\
Related to study drug* & 73 & 24 & 69 \\
All SAEs excluding deaths & 20 & 10 & 29 \\
Deaths & & 7 & 20 \\
Most common events & & 15 & \\
$\quad$ Headache & & 12 & 33 \\
Fatigue & & 11 & 31 \\
Nausea & 8 & 23 \\
Back pain & & 8 & 23 \\
Abnormal hepatic function & & & \\
\hline
\end{tabular}

*According to the investigator. SAEs: serious adverse events. tinuation in 5 patients and led to halving the bosentan dose to $250 \mathrm{mg}$ bid in 1 patient.

\section{Discussion}

Administration of bosentan to patients with stage IV metastatic melanoma resulted in stable disease in 6 of 35 patients at week 12 of treatment, and in 5 of 35 patients at week 24 or later. Five of these 6 patients received bosentan as first-line therapy. No patients experienced complete or partial response. Progressive disease was observed in 17 (49\%) patients at week 12 and in $25(71 \%)$ patients at the end of the study.

Disease stabilization in 2 patients treated by bosentan for more than 26 months is intriguing, but is also consistent with the natural history of melanoma in some individuals.

The profile of AEs was consistent with that associated with the use of bosentan and with the nature of the underlying disease. Overall, the dose of $500 \mathrm{mg}$ bid was well tolerated in this patient population with stage IV metastatic melanoma. Consistent with the fact that a larger dose of bosentan was used in this trial, there was a significantly higher incidence of increased aminotransferases compared to the lower doses of $125 \mathrm{mg}$ bid given to patients with pulmonary arterial hypertension.

\section{Conclusions}

This study shows that bosentan administered at a dose of $500 \mathrm{mg}$ bid was well tolerated in patients with metastatic melanoma without any unexpected adverse event.

The results of this proof-of-concept clinical study suggest that bosentan might have benefit in disease stabilization in this patient population. The potential role of endothelin receptor antagonists such as bosentan in the treatment of patients with metastatic melanoma should be further assessed in randomized controlled studies; for example, in combination with other anticancer drugs.

Acknowledgment The study was performed by Actelion Pharmaceuticals Ltd, Allschwil, Switzerland.

\section{References}

1. Balch CM, Buzaid AC, Soong SJ, Atkins MB, Cascinelli N, Coit DG, Fleming ID, Gershenwald JE, Houghton AJr, Kirkwood JM, McMasters KM, Mihm MF, Morton DL, Reintgen DS, Ross MI, Sober A, Thompson JA, Thompson JF (2001) Final version of the American Joint Committee on cancer staging system for cutaneous melanoma. J Clin Oncol 19:3635-3648

2. Thompson JF, Scolyer RA, Kefford RF (2005) Cutaneous melanoma. Lancet 365:687-701 
3. Eigentler TK, Caroli UM, Radny P, Garbe C (2003) Palliative therapy of disseminated malignant melanoma: a systematic review of 41 randomised clinical trials. Lancet Oncol 4:748-759

4. Khayat D, Meric J-B, Rixe O (2004) Systemic chemotherapy and biochemotherapy for non-resected and metastatic melanoma. In: Thompson JF, Morton DL, Kroon BBR (eds) Textbook of Melanoma. Martin Dunitz, London, pp 586-601

5. Avril MF, Aamdal S, Grob JJ, Hauschild A, Mohr P, Bonerandi JJ, Weichenthal M, Neuber K, Bieber T, Gilde K, Guillem Porta V, Fra J, Bonneterre J, Saiag P, Kamanabrou D, Pehamberger H, Sufliarsky J, Gonzalez Larriba JL, Scherrer A, Menu Y (2004) Fotemustine compared with dacarbazine in patients with disseminated malignant melanoma: a Phase III study. J Clin Oncol 22:1118-1125

6. Middleton MR, Grob JJ, Aaronson N, Fierlbeck G, Tilgen W, Seiter S, Gore M, Aamdal S, Cebon J, Coates A, Dreno B, Henz M, Schadendorf D, Kapp A, Weiss J, Fraass U, Statkevich P, Muller M, Thatcher N (2000) Randomized phase III study of temozolomide versus dacarbazine in the treatment of patients with advanced metastatic malignant melanoma. J Clin Oncol 18:158-166

7. Millward MJ, Bedikian AY, Conry RM, Gore ME, Pehamberger HE, Sterry W, Pavlick AC, De Conti RC, Gordon D, Itri LM (2004) Randomized multinational phase 3 trial of dacarbazine (DTIC) with or without Bcl-2 antisense (oblimersen sodium) in patients (pts) with advanced malignant melanoma (MM): Analysis of long-term survival. (Abstract 7505). In: Proceedings of the American Society of clinical oncology (ASCO), New Orleans, 2004 (Post-Meeting Edition) J Clin Oncol 22

8. Baynash AG, Hosoda K, Giaid A, Richardson JA, Emoto N, Hammer RE, Yanagisawa M (1994) Interaction of endothelin-3 with endothelin-B receptor is essential for development of epidermal melanocytes and enteric neurons. Cell 79:1277-1285

9. Hosoda K, Hammer RE, Richardson JA, Baynash AG, Cheung JC, Giaid A, Yanagisawa M (1994) Targeted and natural (piebald-lethal) mutations of endothelin-B receptor gene produce megacolon associated with spotted coat color in mice. Cell 79:1267-1276

10. Ceccherini I, Zhang AL, Matera I, Yang G, Devoto M, Romeo G, Cass DT (1995) Interstitial deletion of the endothelin-B receptor gene in the spotting lethal (sl) rat. Hum Mol Genet 4:2089-2096

11. Lahav R, Ziller C, Dupin E, Le Douarin NM (1996) Endothelin 3 promotes neural crest cell proliferation and mediates a vast increase in melanocyte number in culture. Proc Natl Acad Sci USA 93:3892-3897

12. Imokawa G, Miyagishi M, Yada Y (1995) Endothelin-1 as a new melanogen: coordinated expression of its gene and the tyrosinase gene in UVB-exposed human epidermis. J Invest Dermatol 105:32-37

13. Jamal S, Schneider RJ (2002) UV-induction of keratinocyte endothelin-1 downregulates E-cadherin in melanocytes and melanoma cells. J Clin Invest 110:443-452

14. Mangahas CR, dela Cruz GV, Schneider RJ, Jamal S (2004) Endothelin-1 upregulates MCAM in melanocytes. J Invest Dermatol 123:1135-1139
15. Demunter A, De Wolf-Peeters C, Degreef H, Stas M, Van Den Oord JJ (2001) Expression of the endothelin-B receptor in pigment cell lesions of the skin. Evidence for its role as tumor progression marker in malignant melanoma. Virchows Arch 438:485-491

16. Lahav R, Heffner G, Patterson PH (1999) An endothelin receptor $\mathrm{B}$ antagonist inhibits growth and induces cell death in human melanoma cells in vitro and in vivo. Proc Natl Acad Sci USA 96:11496-11500

17. Bagnato A, Rosano L, Spinella F, Di Castro V, Tecce R, Natali PG (2004) Endothelin B receptor blockade inhibits dynamics of cell interactions and communications in melanoma cell progression. Cancer Res 64:1436-1443

18. Sekulic A, Suresh P, Pittelkow M, Markovic S (2002) Bosentan, a novel endothelin-A and -B receptor antagonist inhibits proliferation of malignant melanoma cells (Abstract) Meeting of the American Association for Cancer Research. Mayo Clinic, Rochester, MN, USA

19. Berger Y, Chapuis Bernasconi C, Juillerat-Jeanneret L (2006) Targeting the endothelin axis in human melanoma: combination of endothelin receptor antagonism and alkylating agents. Exp Biol Med 231:in press

20. Egidy G, Peduto Eberl L, Valdenaire O, Irmler M, Majdi R, Diserens AC, Fontana A, Janzer RC, Pinet F, Juillerat-Jeanneret L (2000) The endothelin system in human glioblastoma. Lab Invest 80:1681-1689

21. Eberl L, Valdenaire O, Saintgiorgio V, Jeannin J, Juillerat-Jeanneret L (2000) Endothelin receptor blockade potentiates FasL-induced apoptosis in rat colon carcinoma cells. Int J Cancer 86:182-187

22. Cruz A, Parnot C, Ribatti D, Corvol P, Gasc JM (2001) Endothelin-1, a regulator of angiogenesis in the chick chorioallantoic membrane. J Vasc Res 38:536-545

23. Galie N, Torbicki A, Barst R, Dartevelle P, Haworth S, Higenbottam T, Olschewski H, Peacock A, Pietra G, Rubin LJ, Simonneau G, Priori SG, Garcia MA, Blanc JJ, Budaj A, Cowie M, Dean V, Deckers J, Burgos EF, Lekakis J, Lindahl B, Mazzotta G, McGregor K, Morais J, Oto A, Smiseth OA, Barbera JA, Gibbs S, Hoeper M, Humbert M, Naeije R, Pepke-Zaba J (2004) Guidelines on diagnosis and treatment of pulmonary arterial hypertension. The Task Force on Diagnosis and Treatment of Pulmonary Arterial Hypertension of the European Society of Cardiology. Eur Heart J 25:2243-2278

24. Packer M, McMurray J, Massie BM, Caspi A, Charlon V, Cohen-Solal A, Kiowski W, Kostuk W, Krum H, Levine B, Rizzon P, Soler J, Swedberg K, Anderson S, Demets DL (2005) Clinical effects of endothelin receptor antagonism with bosentan in patients with severe chronic heart failure: results of a pilot study. J Card Fail 11:12-20

25. Therasse P, Arbuck SG, Eisenhauer EA, Wanders J, Kaplan RS, Rubinstein L, Verweij J, Van Glabbeke M, van Oosterom AT, Christian MC, Gwyther SG (2000) New guidelines to evaluate the response to treatment in solid tumors. European Organization for Research and Treatment of Cancer, National Cancer Institute of the United States, National Cancer Institute of Canada. J Natl Cancer Inst 92:205-216 